\title{
LUMINESCENCE EXCITATION BY PROTONS AND ELECTRONS, APPLIED TO APOLLO LUNAR SAMPLES
}

\author{
J. E. GEAKE and G. WALKER \\ UMIST, Manchester, England \\ and \\ A. A. MILLS \\ University of Leicester, England
}

\begin{abstract}
A proton accelerator, modified for work on lunar samples, is described; $60 \mathrm{keV}$ protons at about $1 \mu \mathrm{A} \mathrm{cm}^{-2}$ are used. Luminescence emission spectra in the visible and near IR regions are shown for lunar samples from Apollo 11 and 12, and preliminary results are given for Apollo 14 samples. Lunar samples are compared with terrestrial and meteoritic materials. Plagioclase is found to be the most efficient luminescent material present in the lunar samples, and the activator for its dominant green peak is found to be $\mathrm{Mn}^{2+}$.

Apparatus is described for taking colour photographs of the luminescence emission from rock chips under $6 \mathrm{keV}$ electron excitation. Most of the lunar samples investigated show only plagioclase emission, but one breccia shows a wide variety of colours from different luminescent constituents.
\end{abstract}

\section{Introduction}

All of our lunar fines and rock samples showed some luminescence when excited by either protons or electrons. Visually, the fines showed faint bluish-white emission, whereas the rocks and breccias showed brighter emission, but in most cases only from their plagioclase parts which appeared bluish-white. Only one breccia sample showed a wider variety of luminescence colours. The luminescence emission from the samples was recorded photoelectrically as spectral scans, and photographically as colour photographs of the emission. All the samples were also inspected visually under UV lamps giving mainly $2537 \AA$ and $3650 \AA$ emission, but negligible luminescence was observed.

Our interest in the luminescence of the lunar samples is twofold: firstly, to use the characteristic emission spectra of the minerals concerned (mainly plagioclase) to elucidate the mechanism involved in terms of the crystal field situation, and to identify any doping agents involved; secondly, to use luminescence photography to explore the distribution of the luminescent components, and in particular any variations within individual crystals in the hope of gaining some information about the process, rate and direction of crystallisation. The equipment used for these two types of investigation will now be described, and some of the preliminary results will be summarised.

\section{Proton-Excitation Equipment}

Equipment already existing at Manchester [1] was up-graded for the lunar sample investigation, mainly by cleaning up the vacuum system. The accelerator is shown 


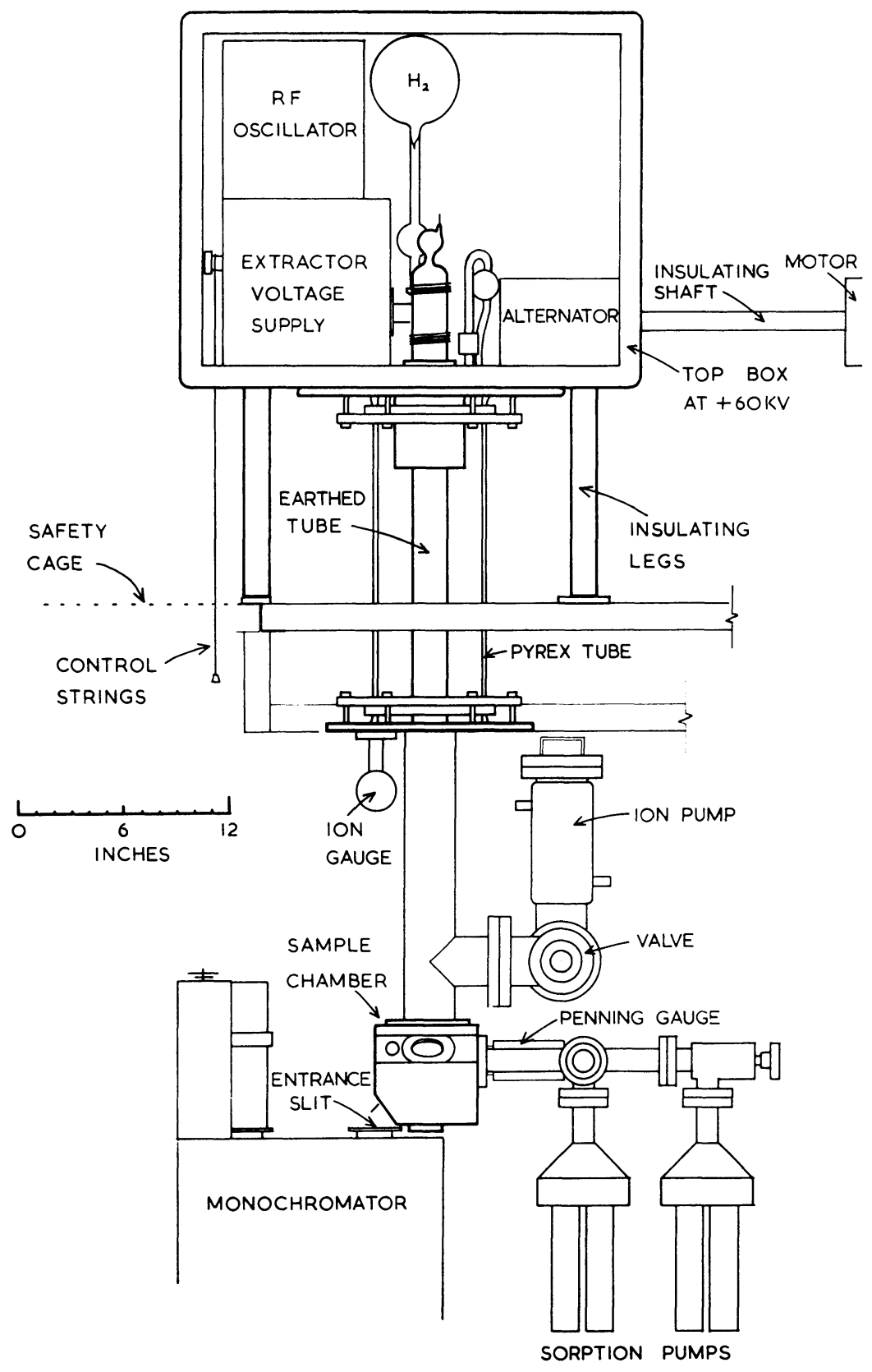

Fig. 1. The proton source and accelerator. An anti-corona collar round the top of the accelerator column and the second photomultiplier to monitor total light are both omitted for clarity. 


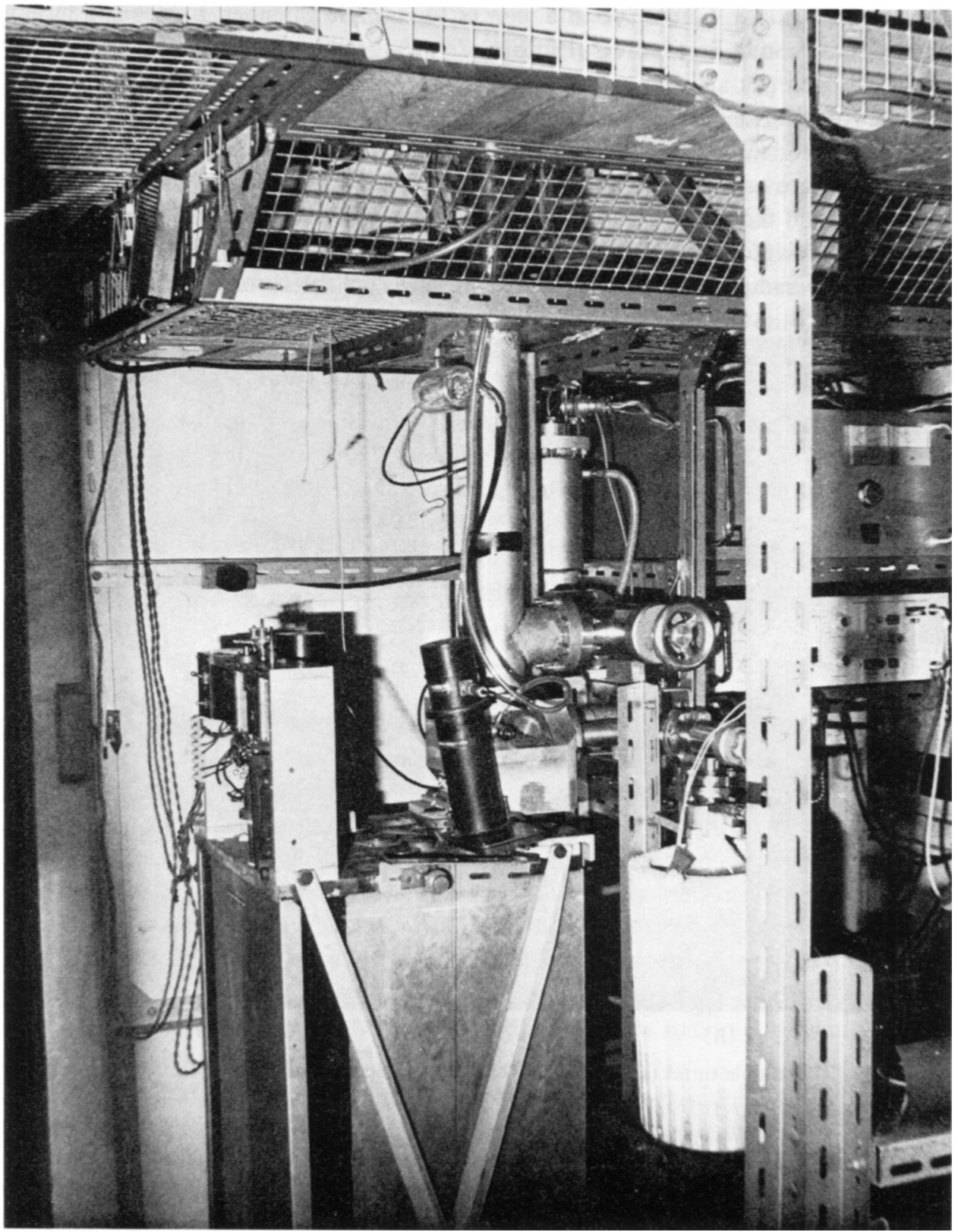

Fig. 2. The sample chamber, pumps and monochromator. 
diagrammatically in Figure 1, and a view of the sample chamber, pumps and monochromator is shown in Figure 2. Protons are produced by ionising spectroscopically pure hydrogen gas at low pressure by means of an RF field at about $20 \mathrm{Mhz}$, and they leave the ion bottle through a $\frac{1}{16}$ in. diam canal. The whole of the top box containing the ion source is at a high positive potential, usually $60 \mathrm{keV}$, and the protons are accelerated by the potential difference between the exit canal of the ion source and the upper end of an axial stainless steel tube at Earth potential; they then coast down inside this tube and hit the target in the sample chamber at the bottom. The samples are placed, four at a time, on the turret shown in Figure 3

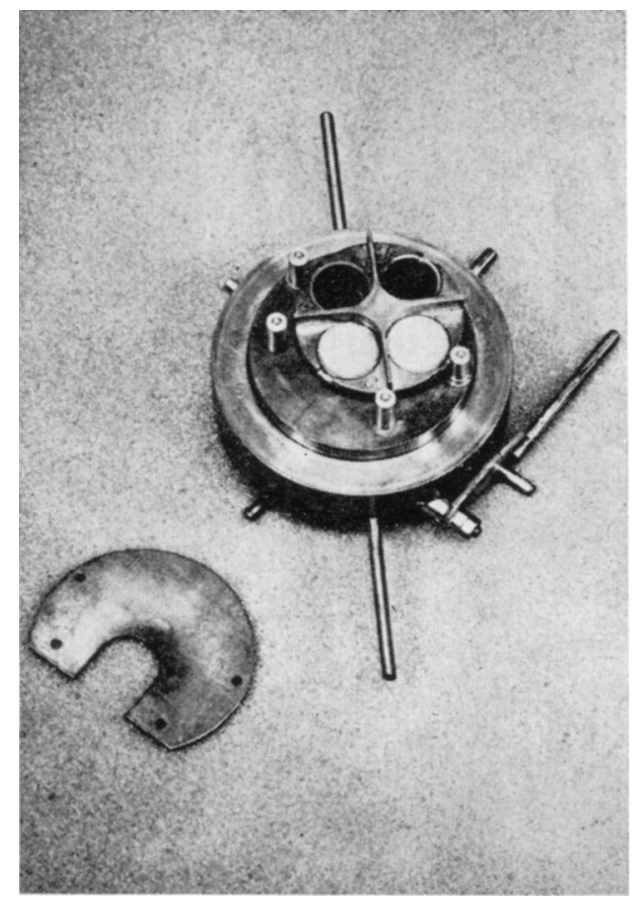

(a)

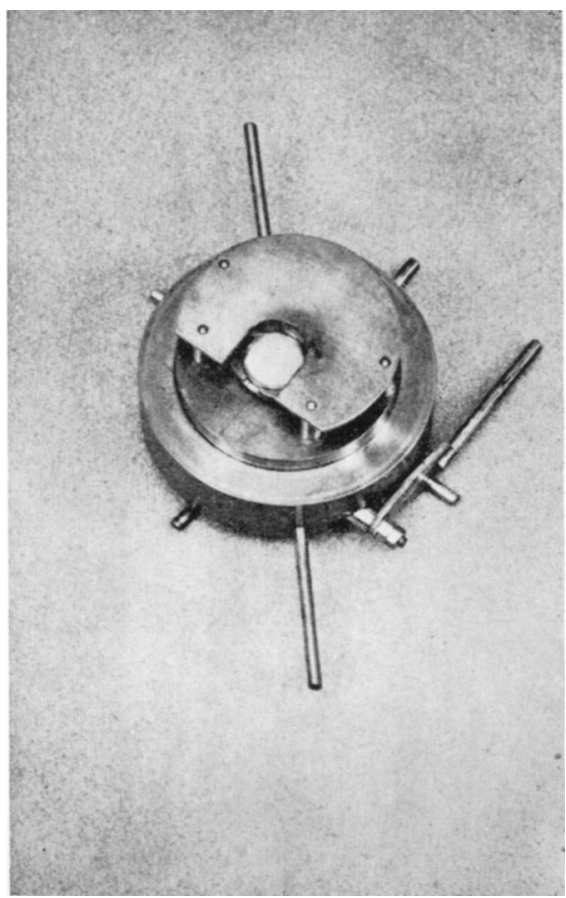

(b)

Fig. 3. The sample turret (a) with the lid off, for loading, (b) with the lid on, ready for use.

which is inserted in the base of the sample chamber; this turret facilitates the intercomparison of samples under the proton beam. A flap valve seals the top of the sample chamber and enables the turret to be removed while keeping the rest of the system under vacuum; it has an insulated shaft and also serves as a collector for beam-current measurement. The field optics of the system results in a beam about $1 \mathrm{in}$. in diameter at the target, with a current density of about $1 \mu \mathrm{A} \mathrm{cm}^{-2}$.

In order to reduce the possibility of contaminating lunar samples all the Neoprene O-rings in the system have been replaced by Viton ones of lower vapour pressure, and the oil diffusion and backing pumps have been replaced by an electrostatic 
getter-ion pump and sorption roughing pumps. The former is a $2 \frac{1}{2}$ in. diam triode pump based on the design of Herb et al. [2], but with the addition of a grid of a type suggested by Cross [3].

The pump consists essentially of a stainless steel tube surrounded by a watercooling jacket, an axial anode and a source of electrons. It operates by the injection of electrons from a tungsten filament into the electrostatic field between the earthed tube, which is the cathode, and the axial anode at $+5 \mathrm{keV}$ consisting of $\frac{1}{16}$ in. diam tungsten rod carrying a $\frac{1}{4}$ in. diam titanium slug. The electrons follow spiral orbits about the central anode, causing ionisation of the residual gas; eventually they hit the titanium slug, causing it to become white hot and to sublime onto the walls of the pump, thereby 'gettering' the active gases. Inert gases are pumped by ionisation followed by physical burial of the positive ions in the pump wall by titanium. The pumping speed for nitrogen is about 150 litre $\mathrm{s}^{-1}$. The action of the grid wires placed between the anode and the cathode is to improve the sticking probability of the inert gas ions which hit the pump wall, by ensuring that they arrive with an energy of at least $1 \mathrm{keV}$. In order to increase the active life of the pump between overhauls the filament is duplicated. It is found to be advantageous to keep the pump itself under as good a vacuum as possible between runs; it is therefore connected to the system through a large all-metal isolating valve.

Two four-tube sorption pumps cooled in liquid nitrogen are used to pump the system down initially, to about $10^{-3}$ torr, at which point the ion pump valve is opened and the sorption pumps are isolated and re-activated. Although the ion pump itself is capable of a very low ultimate pressure, in the present rather long and complicated vacuum system the lowest pressure usually attained, before introducing hydrogen into the ion source, is about $10^{-6}$ torr; after admitting hydrogen, through a needle valve, an operating pressure of about $10^{-5}$ torr is reached. This is adequate to permit the proton beam to pass. The vacuum gauges used consist of a Penning gauge on the sample chamber and an ion gauge on the accelerator column; the former is used mainly to monitor the roughing pump pressure and the latter as an aid to adjusting the hydrogen leak on the ion source. Ultimately, the hydrogen leak and the RF oscillator frequency are both adjusted for a maximum beam current, as intercepted by the flap valve.

\section{Luminescence Emission Spectra}

Light emitted by the sample under proton excitation is reflected by two mirrors, one inside the sample chamber and one outside its window, onto the entrance slit in the horizontal top plate of an Ebert monochromator [4]. This uses a $5 \times 4$ in. Bausch and Lomb grating with 1200 lines $\mathrm{mm}^{-1}$, and has a dispersion of $8 \AA \mathrm{mm}^{-1}$ in the first order. The spectrum is scanned by tilting the grating, by means of a synchronous motor and a gear-driven micrometer screw. Light leaving the exit slit is recorded, using an EMI 9558B trialkali photomultiplier for the visible region and a Mullard $150 \mathrm{CVP} \mathrm{Ag}-\mathrm{AgO}-\mathrm{Cs}$ photomultiplier, with its photocathode cooled to liquid- 


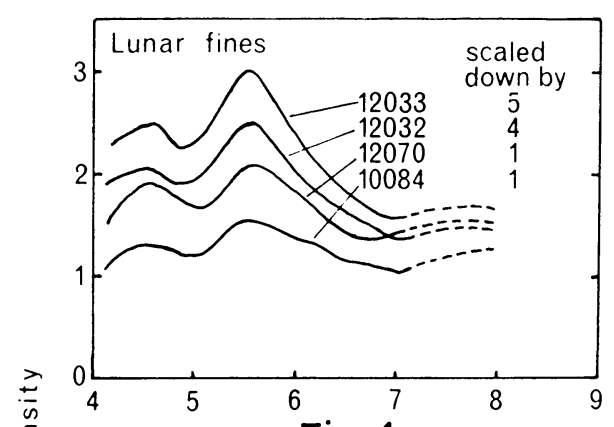

Fig. 4

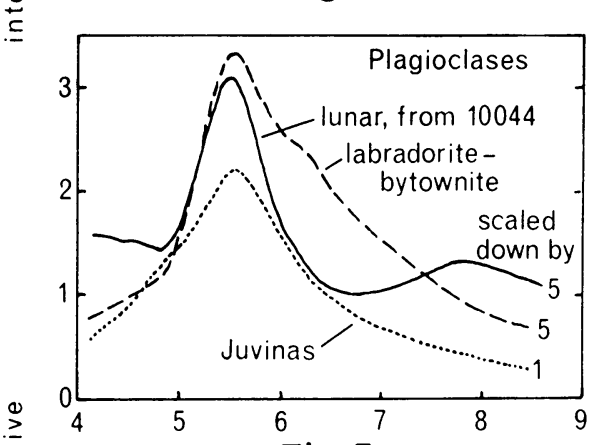

Fig. 5

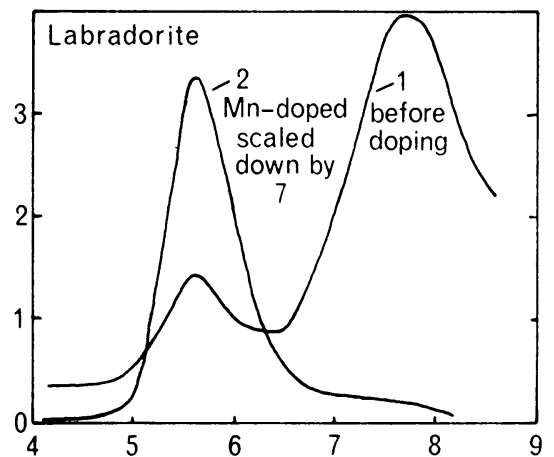

Fig. 6

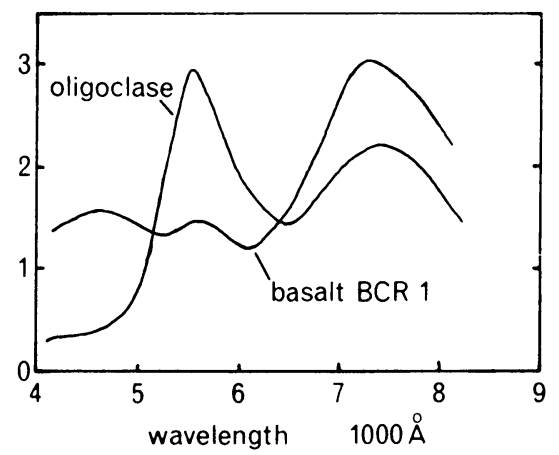

Fig. 7

Figures 4-7. Luminescence emission spectra with $60 \mathrm{keV}$ proton excitation, using an instrumental profile width of about $200 \AA$. 
nitrogen temperature, for the near IR region. A further photomultiplier monitors the total light and corrects the output for time fluctuations and for efficiency fall-off caused by proton damage. A piece of Polaroid is placed permanently over the entrance slit to minimise the effect of grating anomalies. A Wratten $2 \mathrm{~B}$ filter is used for visible region scans and a Wratten 25 filter for IR scans, to remove errors due to secondorder light. Spectral response calibration is achieved by comparison with a tungsten lamp of known colour temperature.

Figure 4 shows corrected emission spectra for all three of our Apollo 12 fines samples $(12032.39,12033.60$ and 12070.113) [5]; our previously published spectrum for Apollo 11 fines sample 10084.6 is also shown for comparison. We have two types of Apollo 12 fines - 12070.113 is very dark in appearance and resembles the Apollo 11 fines 10084.6, whereas 12032.39 and 12033.60 are much lighter because they contain more plagioclase $\left[(\mathrm{Na}, \mathrm{Ca})(\mathrm{Al}, \mathrm{Si})_{4} \mathrm{O}_{8}\right]$ and less ilmenite $\left[\mathrm{FeTiO}_{3}\right]$, and they are probably ray material [7]. However, all four samples show very similar emission spectra, with a weak $4500 \AA$ peak, a stronger peak at $5600 \AA$, and some emission in the near IR, each of which we ascribe to plagioclase. It is only the efficiencies that are different for the four samples, and these seem to be related to the plagioclase content. The efficiency increases faster than the plagioclase content, probably because there are two effects: as plagioclase is the most efficient luminescing component, more plagioclase means more emission, but it also means a lower content of absorbing material (eg. ilmenite), as indicated by the albedo, so that the emitted light can get out more easily and can better survive scattering by surface roughnesses, giving an even greater apparent efficiency. The true efficiency of the actual luminescing material is probably about the same for all four samples. Preliminary results for two samples of Apollo 14 fines (14157 and 14263) show that their emission spectra are very similar to those for Apollo 11 and 12 samples, as shown in Figure 4, and that their efficiencies are between those for 12070 and 12032 .

The emission spectra of some terrestrial plagioclases are shown in Figures 5, 6 and 7 . Apart from the relative intensity of the IR emission, as discussed later, the main difference is that their overall efficiencies are 10-100 times that of the lunar fines. However, the plagioclase found in lunar rocks does have an efficiency comparable with that of terrestrial plagioclase; thus the separated plagioclase from lunar rock sample 10044.43 has about the same efficiency as labradorite-bytownite, as shown in Figure 5. The low efficiency of the lunar fines is probably due to the admixture of the plagioclase with opaque material, and also possibly to the coating of individual grains with a thin opaque layer, as suggested by Hapke et al. [8,9] and others.

\section{The Cause of Plagioclase Emission}

Reasoning from crystal field theory suggested that the prominent green peak shown by both lunar and terrestrial plagioclase might be caused by the presence of $\mathrm{Mn}^{2+}$. To test this, the proton-excited emission spectrum of a typical terrestrial plagioclaselabradorite-was scanned, as shown in Figure 6, curve 1. It was then doped with 
about $0.1 \%$ of $\mathrm{Mn}$ by heating it to $1050^{\circ} \mathrm{C}$ for $30 \mathrm{~min}$ in argon with $\mathrm{MnSO}_{4}$. The result was a 16-fold increase in the height of the green peak, as shown by curve 2 , accompanied by a halving of the blue and IR emission. In order to check that simply heating the plagioclase was not producing the change (perhaps by converting the lowtemperature form of anorthite-Ca-rich plagioclase-to the high-temperature form) a further sample was given the same heat treatment without any $\mathrm{MnSO}_{4}$ : its emission spectrum was found to be unchanged.

Plagioclases usually contain more than $100 \mathrm{ppm}$ of $\mathrm{Mn}$, as determined by X-ray fluorescence analysis. The plagioclase separated from lunar rock 10044 was found to contain about $200 \mathrm{ppm}$ of $\mathrm{Mn}$ (about the same as an average terrestrial sample); its emission spectrum is shown in Figure 5-it has a strong green peak like that for the Mn-doped labradorite in Figure 6, but rather more blue and IR emission as well. Sippel and Spencer [10] have pointed out that albite (Na-rich plagioclase) does not show a green peak, and they conclude that when it is present this peak is caused by a divalent activator substituting for $\mathrm{Ca}^{2+}$ in the lattice. Our results seem consistent with $\mathrm{Mn}^{2+}$ being the activator responsible. The situation may be compared with that of the $\mathrm{Mn}^{2+}$ emission peak which is found for $\alpha-\mathrm{CaSiO}_{3}: \mathrm{Mn}(\alpha$-wollastonite) and which also occurs at about $5600 \AA$ [11]. We have discussed the formation and location of this green peak in detail elsewhere [5] in terms of the crystal field situation, and have shown that on theoretical grounds $\mathrm{Mn}^{2+}$ is a likely activator.

The other main emission bands of plagioclase are one in the blue and one in the near IR. All plagioclases show some blue emission, as do iron-free enstatites, forsterites and many other silicates [12]. The emission band is broad, with a somewhat variable peak wavelength. It is likely that this blue emission band has a similar origin in all these relatively iron-free silicates, and that it is due to a particular type of lattice defect rather than to any impurity activator. Sippel and Spencer [10] have found that some heavily shocked plagioclases and silica mineral phases show an enhanced blue emission, which also implies that lattice defects are responsible.

Most terrestrial plagioclases show a prominent emission band in the near IR, as shown for labradorite in Figure 6, curve 1, and for basalt BCR-1 in Figure 7. However, sometimes this band is only of comparable intensity to the green band, as for oligoclase (Figure 7), and occasionally it is virtually absent as for labradorite-bytownite (Figure 5). We differ here from Sippel and Spencer [10] who suggest that all terrestrial plagioclases show a strong IR emission band. The lunar materials we have examined tend to show a weak emission band in the IR, as shown by the four samples of lunar fines in Figure 4 and by the separated lunar plagioclase in Figure 5. We also find that meteorites in which plagioclase is the main luminescent phase, e.g. hypersthene and bronzite chondrites and pyroxene-plagioclase achondrites, do not show an IR peaksee, for example, Juvinas (a pyroxene-plagioclase achondrite) shown in Figure 5.

The wavelength of the IR emission peak is variable, ranging from about 7300 to $7700 \AA$, and the band is usually broader than the green band. It is often the dominant emission band for terrestrial plagioclase, as for the labradorite examined, and it does not appear to be associated with manganese since the addition of manganese was 
found to reduce its intensity, as shown in Figure 6. If this emission is due to an impurity activator than it should be possible by selective doping with suspected activators to identify the element responsible, which is probably present naturally in amounts of not less than $100 \mathrm{ppm}$. As most plagioclases contain up to $1 \%$ of iron, and as $\mathrm{Fe}^{2+}$ often gives rise to absorption bands in the near IR in silicates, this might be a possible candidate, although $\mathrm{Fe}^{2+}$ also acts as a luminescence 'killer' in silicates. Preliminary tests in which iron was added to labradorite (by heating it to $1050^{\circ} \mathrm{C}$ in argon with $0.1 \%$ hydrated ferrous sulphate) did not show any increase in the (already high) IR emission-in fact there appeared to be a slight reduction. A program of selective doping and of comparative analysis of different plagioclases is now under way, in the hope of identifying the cause of the IR emission.

\section{Cathodoluminescence}

The distribution of the luminescent constituents of our lunar rock and breccia chips has been investigated by taking colour photographs of the emission. As electrons cause much less damage than protons, giving brighter and more constant emission for the same energy, electron excitation is to be preferred when using visual or photographic methods which require long exposures.

Several workers have in the past investigated electron-excited luminescence ('cathodoluminescence'); the brilliant luminescence exhibited by diamonds, rubies, and other gems when exposed to cathode rays was discovered in the 1870's by Crookes [13], and investigated with the assistance of Maskelyne. Their technique was simply to seal the stones into a glass discharge tube opposite a cathode which could be connected to an induction coil. Besides the bright and sometimes varying luminescence, Crookes also reported the generation of polarised luminescent light, the loss of efficiency on continuous bombardment, and the brown stain which readily forms on any surface subjected to such bombardment.

The identical technique was applied to meteorites by Buddhue [14] in 1941. He found enstatite to be the most active mineral, usually giving a blue luminescence but with occasional red grains. He examined the spectrum of the glow (apparently with a direct-vision spectroscope) and states that phosphorescent glows were also observed for periods up to a minute. The luminescence was found to be brighter in cathode rays than in beams of ions.

The combination of discharge tube excitation with microscopic observation seems to have been first accomplished by Gallup [15]. He describes a simple device for the direct investigation of manganese-activated calcium silicate phosphors.

It was, however, the development and general use of the analytical electron microprobe which really kindled interest in cathodoluminescence. Rocks and minerals could be seen glowing in the electron beam, and otherwise invisible growth structures were sometimes delineated [16]. It was quickly realised that for visual investigation of morphology the complication and expense of a microprobe was unnecessary, and Sippel [17] described apparatus whereby specimens could be moved and viewed 
beneath a microscope while keing irradiated with an electron beam generated by a glow discharge. Simple electron-irradiation devices were also made by other workers, and successfully applied to problems in terrestrial mineralogy $[18,19]$.

Rising interest in transient lunar phenomena and the nature of the lunar surface led to Derham and Geake's [20] demonstration of the luminescence of meteorites when bombarded with protons. Enstatite was identified as the constituent generally responsible, luminescing red or blue according to the amount of activating manganese present [24]. Cathodoluminescence and microprobe studies by other workers have confirmed the attribution to manganese.

Sippel and Spencer [10] have applied their electron excitation technique to lunar crystalline rocks and breccias, while other workers have investigated the proton excitation of these materials $[5,6,21,22]$.

\section{Electron-Excitation Apparatus for Luminescence Photography}

Apparatus based on Sippel's design was constructed by Mills in 1966 in order to examine the cathodoluminescence of meteorites and tektites. This apparatus has now been used at Leicester for the present work on lunar samples, and one arrangement of it is shown in Figure 8. Important features of the design are:

(a) A vacuum chamber large enough to accommodate either centimetre-size rock fragments or thin sections, and reversible so that samples can be irradiated from either above or below.,

(b) Provision for examination of the sample by either transmitted or surface luminescence or incident light, with or without crossed polarizers.

(c) Provision for $x$ and $y$ positioning of the sample by means of push-rods working through 0-ring seals.

(d) Provision for using either air or hydrogen (at a pressure of about $2 \times 10^{-2}$ torr) as the discharge gas; the use of hydrogen minimises background illumination from the glow discharge.

(d) A cylindrical depression, $3 \mathrm{~mm}$ in diam and $1 \mathrm{~mm}$ deep, in the centre of the aluminium cathode; this helps to form and stabilise the electron beam.

A $30 \mathrm{keV}$ power supply, with a $33 \mathrm{M} \Omega$ series stabilising resistance chain, results in a potential difference of about $6 \mathrm{keV}$ across the discharge tube in normal operation. The current density at the sample is about $8 \mu \mathrm{A} \mathrm{cm}{ }^{-2}$. The anode and the sample chamber are at earth potential. The anode has a central hole surrounded by a crown of needle points which help to start the discharge; the electron beam passes through this hole and coasts through field-free space to the sample. A sheet-lead X-ray shield surrounds the discharge tube during operation, and the viewing windows are of lead glass. A rotary oil pump is sufficient to produce the vacuum required; it is fitted with a back-streaming trap containing activated alumina and Linde $5 \mathrm{~A}$ molecular sieve material. The use of a 'soft' vacuum simplifies construction and operation, and obviates the charging problems encountered when non-conducting materials are irradiated in a hard vacuum. 


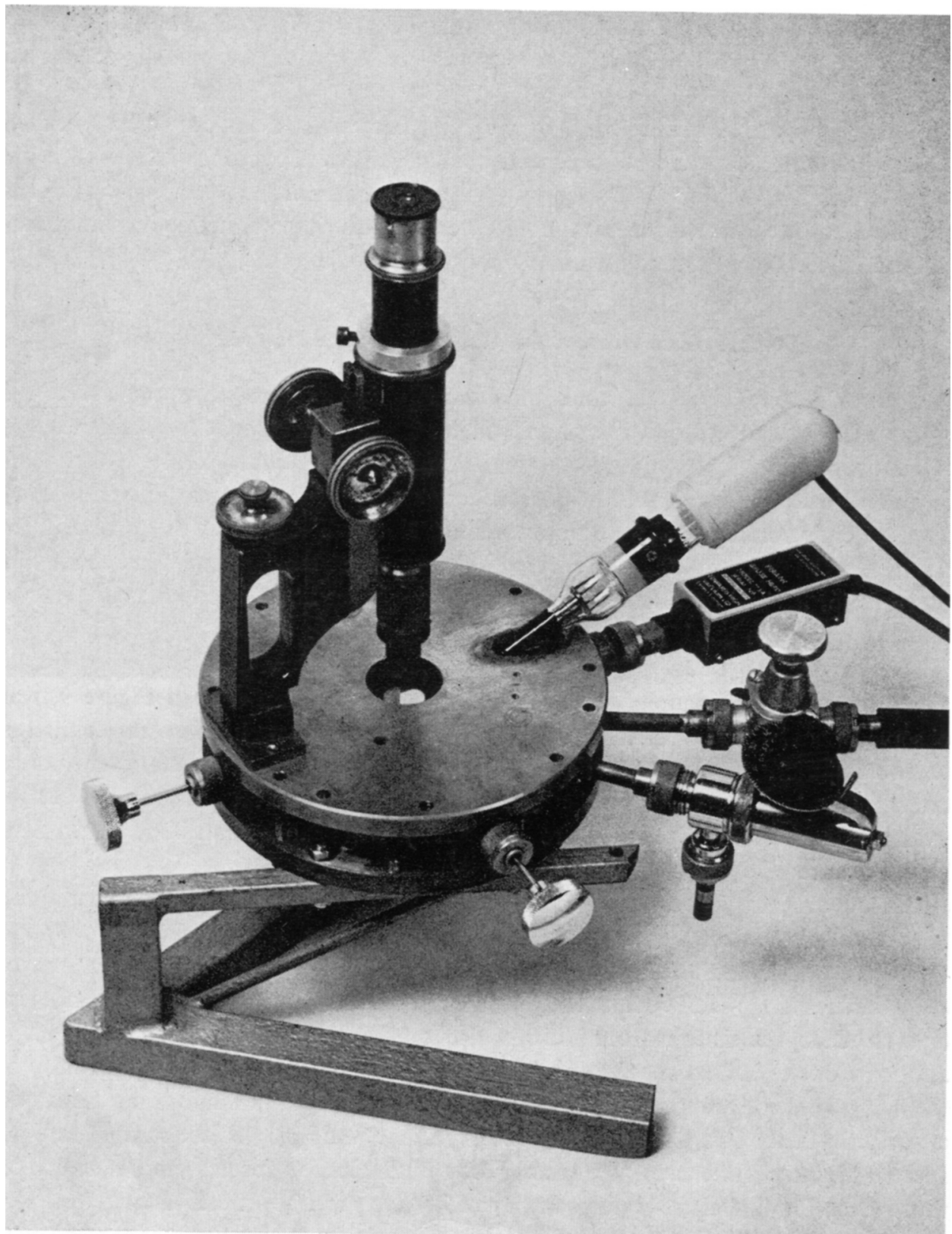

Fig. 8. Apparatus for observing luminescence under electron excitation, shown with the microscope attached, but without the camera. The discharge tube irradiates the sample from above in this arrangement; clockwise from the discharge tube are the Penning gauge head, the vacuum line, the gas inlet needle valve and the two sample-positioning rods. 
An alternative discharge tube is under construction, of the type developed by Dugdale [23]; it employs a hollow-anode electron-beam source, and should produce a higher beam intensity.

Figure 8 shows the arrangement of the apparatus as used for our lunar work, in which the sample is both irradiated and observed from above. It is shown with the microscope attached, for visual inspection; for photographic use a $35 \mathrm{~mm}$ single-lens reflex camera is either attached to the microscope or else it is used directly, with extension tubes, to take macroscopic photographs.

\section{Luminescence Distribution Within Rock and Breccia Samples}

All of our Apollo 11 and 12 rock and breccia chips have been inspected with the cathodoluminescence apparatus, and in all cases where significant luminescence was observed colour photographs of the emission were taken. A typical exposure was $30 \mathrm{~s}$ at $\mathrm{f} / 2$ with $\times 1.85$ magnification, on Kodak High-Speed Ektachrome (Daylight) reversal film; some microphotographs were taken with exposures of up to half an hour. The flatter parts of the rough chips were chosen, as the depth of focus obtainable was a major limitation. The results cannot be reproduced here in colour, but some of them are shown in black and white in Figures 9 to 12 .

All our rock chips showed bluish-white luminescence from their plagioclase parts, and little else. For example, rock chip 10058.38, which is shown in Figure 9, was observed visually and so arranged that one could 'blink' from luminescence emission to direct illumination. It was evident that of its three main constituents, the white or clear plagioclase parts were luminescing bluish-white or blue, whereas the brown pyroxene and black ilmenite were completely non-luminescent. One small lath luminesced red.

Other rocks showed coarse or fine patterns of plagioclase emission, consistent with their stated grain sizes. Figure 10 shows the luminescence e mission from two Apollo 12 rocks: (a) is a medium-grained rock, 12051, showing fan-shaped groups of plagioclase laths, and (b) is of rock 12002 showing smaller and more irregular plagioclase crystals. Colour variations from bluish-white to blue across some rl igioclase crystals, and from one crystal to another, probably indicate variations in the concentration of the manganese activator, an effect that we have also noticed with manganese-activated enstatite in meteorites [24]. We have observed that when plagioclase samples are inspected visually while being scanned in our luminescence spectrophotometer, then those whose luminescence appears nearly white give spectral profiles having a moderate green peak; when this peak is weak the emission appears blue, and when it is very strong, as for the Mn-doped labradorite shown in Figure 6 and for the plagioclase-rich meteorite Juvinas shown in Figure 5, the appearance is yellow-green. Several of the lunar rock chips also showed occasional small pink-luminescent grains. Some chips showed very bright blue-luminescent specks, but these we take to be contamination, probably by saw material.

Two breccias were available, both from Apollo 11, and their luminescence appear- 


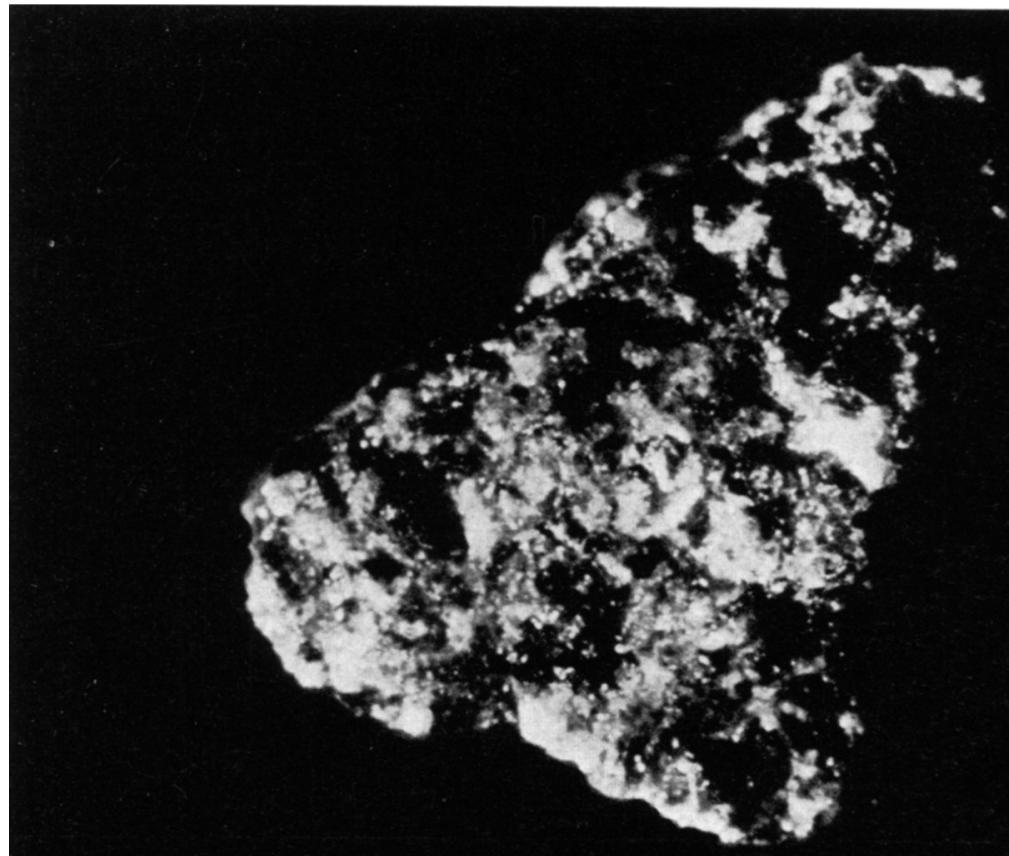

(a)

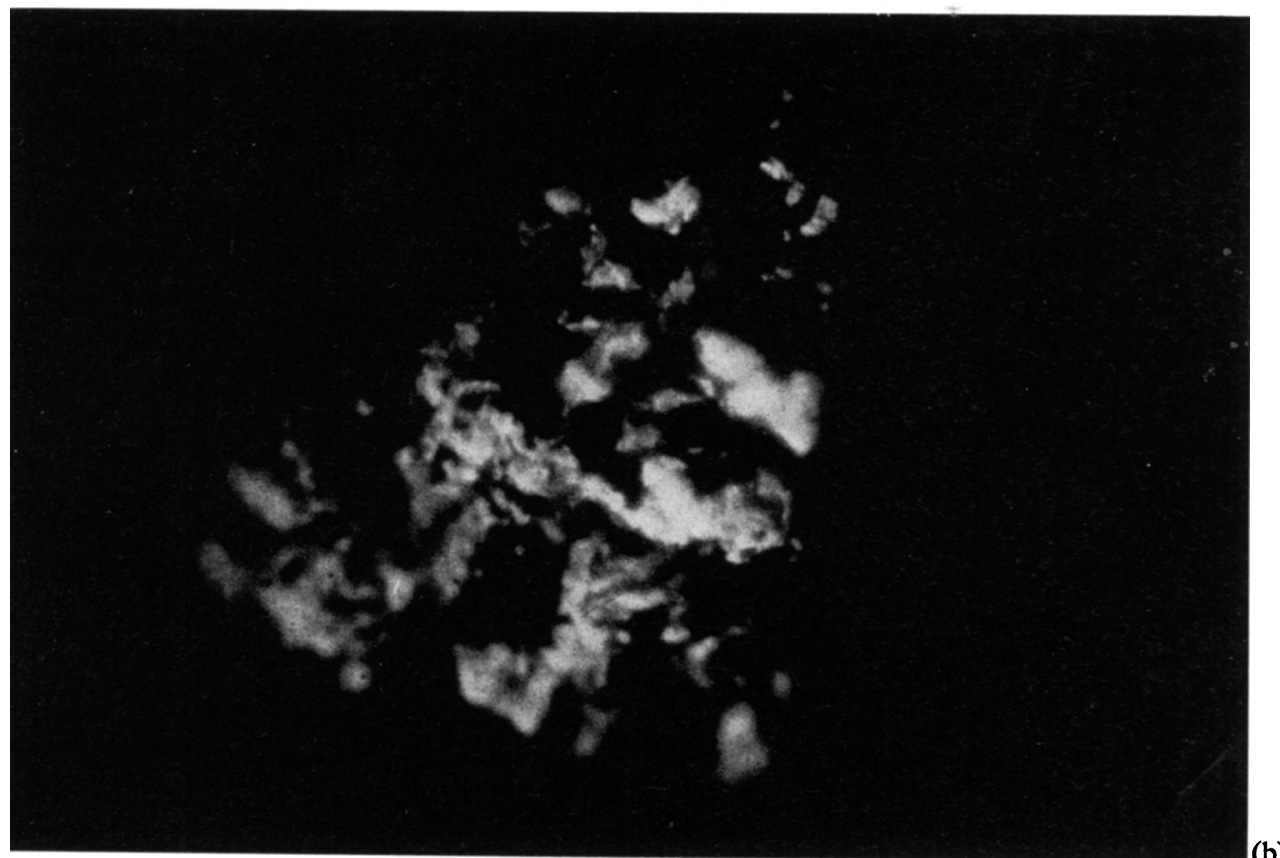

Fig. 9. Rock sample 10058.38 (a) in white light, (b) luminescence emission. The height of each print represents about $1 \mathrm{~cm}$. 

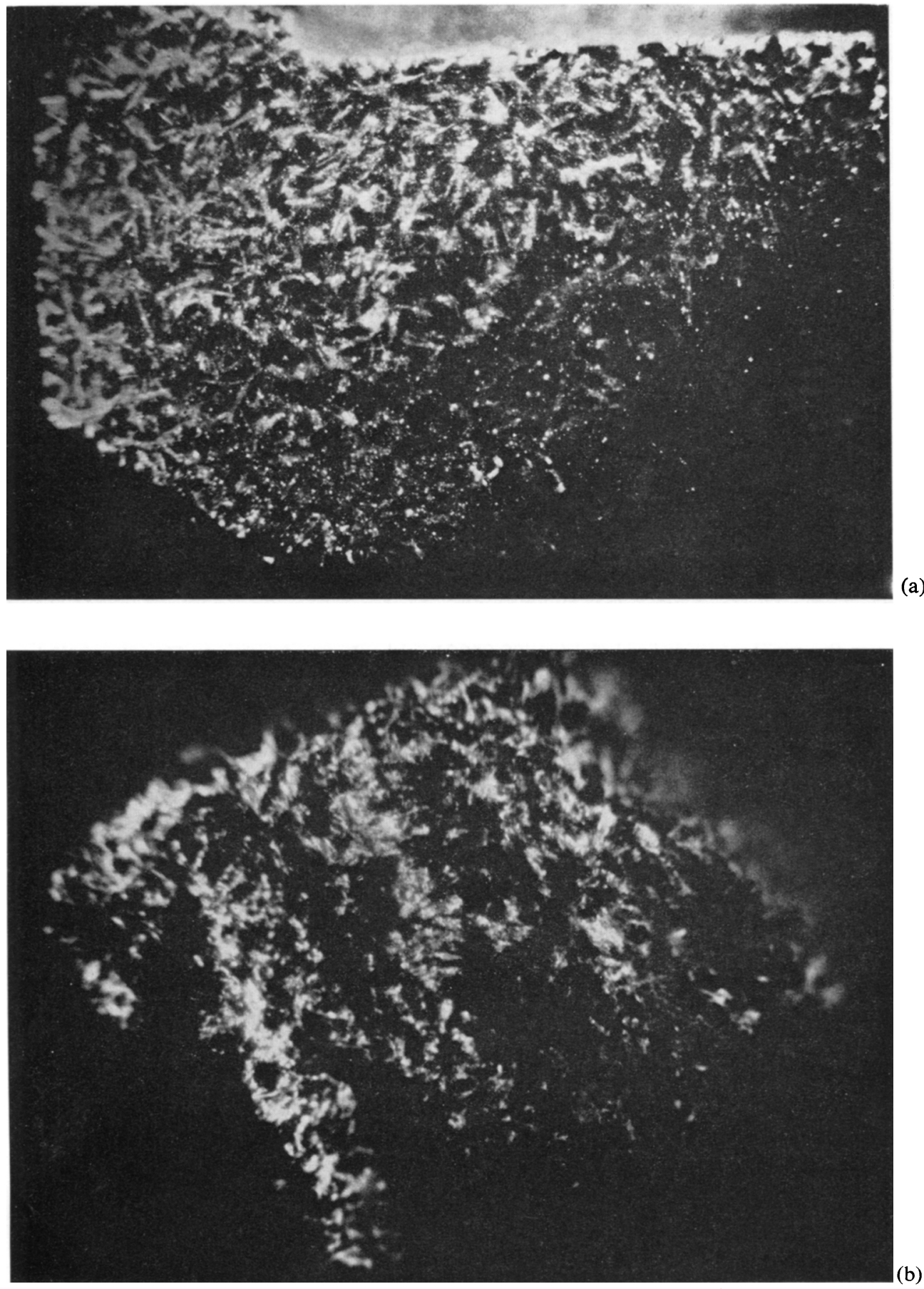

Fig. 10. Luminescence emission of two Apollo 12 rock samples: (a) 12051.16, (b) 12002.102. The height of each print represents about $1 \mathrm{~cm}$. 

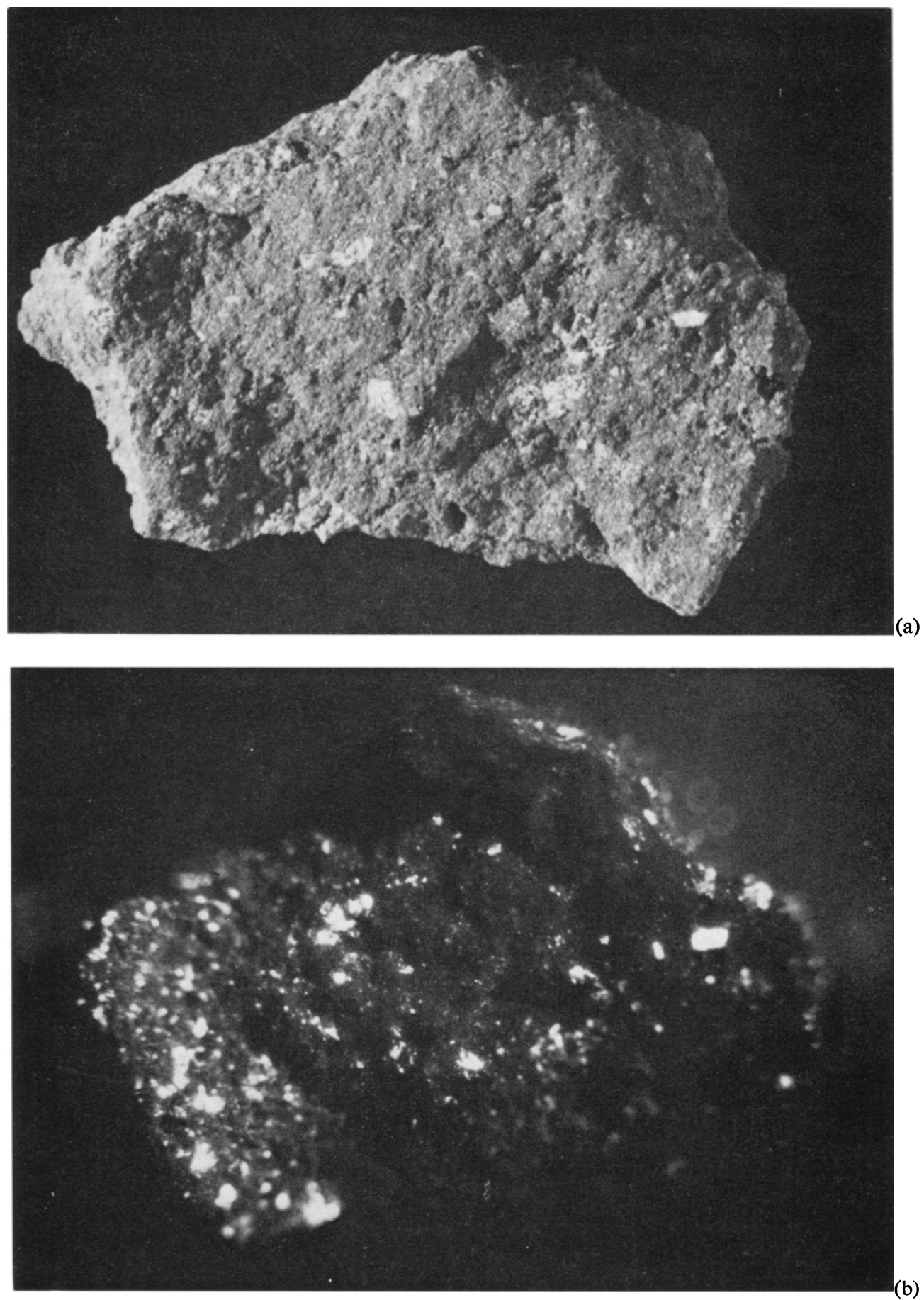

Fig. 11. Breccia sample 10023.8, (a) in white light, (b) luminescence emission. The height of each print represents about $1 \mathrm{~cm}$ 


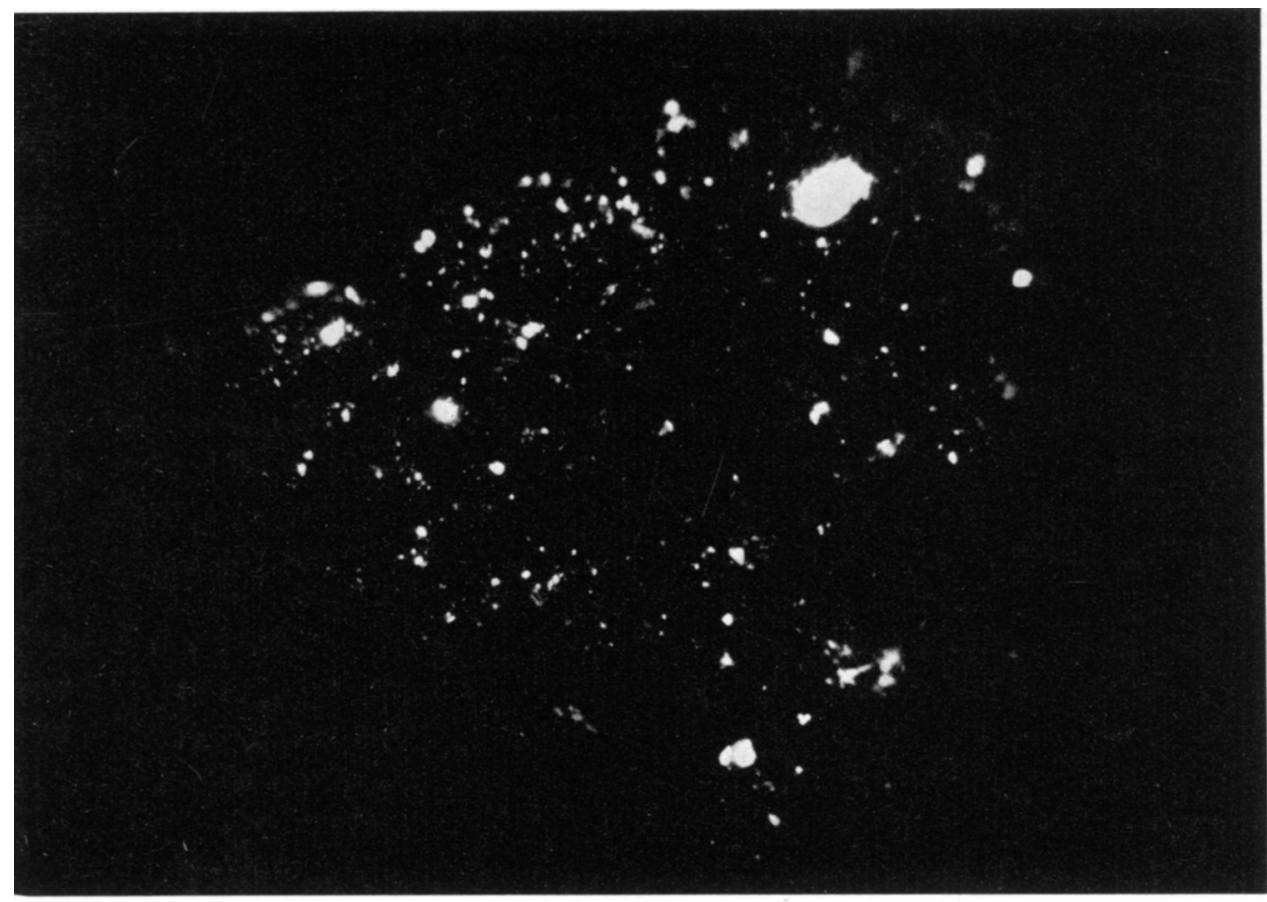

(a)

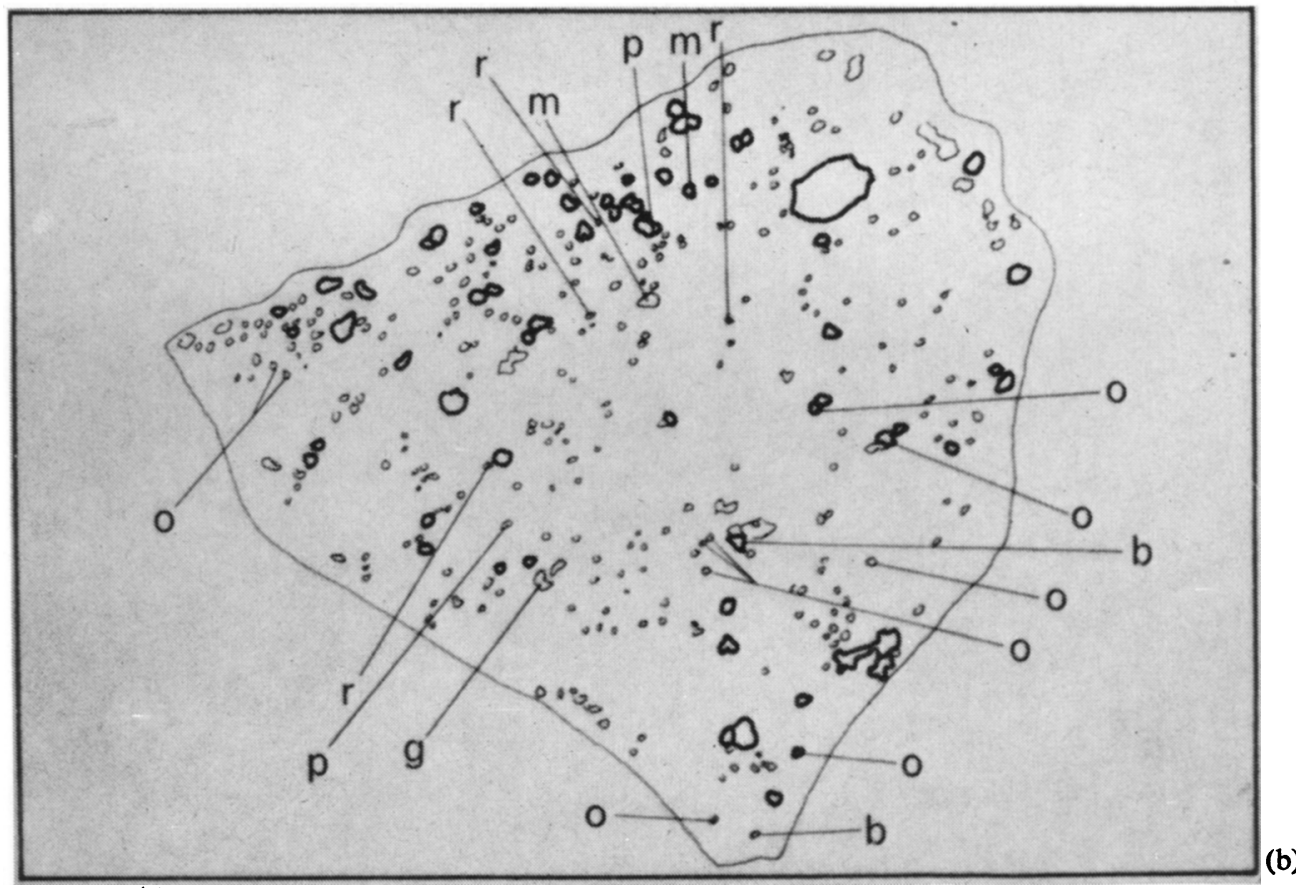

Fig. 12. (a) Luminescence emission of breccia sample 10059.36, (b) a map indicating of some of the luminescence colours seen: $r=$ red, $p=$ pink, $o=$ orange, $g=$ green, $b=$ blue, $m=$ mauve. Most of the other emitting regions appear white or bluish white. The height of the print represents about $1 \mathrm{~cm}$. 
ance was quite different from that of the rocks, showing many luminescent grains embedded in a non-luminescent matrix. Sample 10023.8 (Figure 11) showed whiteluminescent grains (probably plagioclase), and little else, but sample 10059.36 (Figure 12) showed a surprising variety of emission colours including red, orange, yellow, green, blue and a range of mauves and pinks which usually vary in hue across the grains concerned. Luminescent grains of all sizes from $1 \mathrm{~mm}$ or so down to a few $\mu \mathrm{m}$ are seen. This one breccia sample appears to contain so much luminescence information that it would be useful to identify the materials responsible, but this will only be practicable with a thin section of the same sample on which electron microprobe analysis can be carried out, using the luminescence photograph as a map. Luminescence may then provide a quick and almost non-destructive method of exploring the surface of a rock, and of identifying at least some of its constituents, without making sections. We have noticed that most of the rock chips show a few grains of some luminescence colour other than that of plagioclase.

It is already possible to say that the red luminescence may be due to apatite. We have shown by electron microprobe analysis that some luminescent regions in two hypersthene chondrite meteorites (Appley Bridge and Mangwendi) contained $\mathrm{Ca}$ and $\mathrm{P}$, but no $\mathrm{Fe}$, indicating apatite. The emission varied from red to orange across the grains, probably due to a variation in the $\mathrm{Cl} / \mathrm{F}$ ratio.

Two samples of lunar fines (10084.6 and 12032.39) have also been observed and photographed under electron excitation. They were much fainter than the luminescent parts of the rocks: they both appeared generally mauve, with brighter white-luminescent specks and larger grains, which were probably plagioclase. No other colours were seen. This low efficiency in comparison with similar constituents in rock samples is probably due to the surface damage and grain-coating effects discussed earlier.

\section{Conclusions}

We conclude that for the Apollo lunar material we have examined the main luminescent constituent is plagioclase, that the main emission of lunar plagioclase is a green peak at about $5600 \AA$, and that the cause of this peak is about a hundred parts per million of manganese in the form of $\mathrm{Mn}^{2+}$ substituting for $\mathrm{Ca}^{2+}$ in the plagioclase lattice. The less efficient blue emission at about $4500 \AA$ is probably caused by a lattice defect and is common to most silicates; the weak IR peak at about $7700 \AA$ is probably caused by an impurity activator yet to be identified. Most terrestrial plagioclases show much stronger IR emission than the lunar material.

Electrons and protons in the $\mathrm{keV}$ region are both effective in exciting luminescence in lunar material; UV is ineffective. The overall efficiencies of lunar rock and breccia samples depend largely on their content of plagioclase, which itself has an efficiency of about $10^{-3}$. Samples of lunar fines also have efficiencies depending on their plagioclase content, but they are at least an order of magnitude less efficient than the rock samples possibly because the grains have a thin surface layer which is either opaque or damaged. Two light-coloured Apollo 12 fines samples, thought to be ray material, 
are an order of magnitude more efficient than the dark fines material from Apollo 11 and 12 , which has an efficiency of about $10^{-5}$.

Lunar rock and breccia samples generally show blue-white luminescence distributed texturally as their plagioclase component, with a few grains of other luminescent materials one of which may be apatite. One breccia (10059) shows a wide variety of luminescence colours from components yet to be identified.

\section{Acknowledgements}

We are grateful to M. L. Gould for technical assistance; to F. Kirkman of UMIST, Leicester University photographic section, Hull University photographic section, N. W. Scott, D. Rendell and Colour $061 \mathrm{Ltd}$. for photographic assistance; to G. F. J. Garlick of Hull University Physics Dept. for the loan of the terrestrial plagioclase samples and for carrying out the Mn doping; to J. Zussman, A. C. Dunham and J. Esson of Manchester University Geology Dept. for advice and for Mn determination by X-ray fluorescence analysis, also for the loan of the sample of separated lunar plagioclase; to P. Suddaby of the Geology Dept. Imperial College, University of London, for help with the electron micro-probe investigation of meteorites; to C. J. E. Kempster for advice on the structure of plagioclase; to The British Museum (Natural History) for the loan of meteorite samples; to The Science Research Council for financial support, and finally to NASA, and especially to all the Apollo astronauts, for providing the lunar samples.

\section{References}

[1] Derham, C. J. and Geake, J. E.: 1963, Technical Note No. 2, USAF Contract AF61(052)-379.

[2] Maliakal, J. C., Limon, P. J., Arden, E. E., and Herb, R. G.: 1964, J. Vac. Sci. Tech. 1, 54.

[3] Cross, J.: private communication.

[4] Geake, J. E. and Lumb, M. D.: 1963, Technical Note No. 1, USAF Contract AF61(052)-379.

[5] Geake, J. E.: Walker, G., Mills, A. A., and Garlick, G. F. J.: 1971, Proc. Second Lunar Science Conference, Geochim. Cosmochim. Acta Suppl. 2 3, 2265.

[6] Geake, J. E., Dollfus, A., Garlick, G. F. J., Lamb, W., Walker, G., Steigmann, G. A., and Titulaer, C.: 1970, Proc. Apollo 11 Lunar Science Conference, Geochim. Cosmochim. Acta Suppl. $13,2127$.

[7] Dollfus, A., Geake, J. E., and Titulaer, C.: 1971, Proc. Second Lunar Science Conference, Geochim. Cosmochim. Acta Suppl. 2 3, 2285.

[8] Hapke, B. W., Cohen, A. J., Cassidy, W. A., and Wells, E. N.: 1970, Proc. Apollo 11 Lunar Science Conference, Geochim. Cosmochim. Acta Suppl. 1 3, 2199.

[9] Hapke, B. W., Cassidy, W. A., and Wells, E. N.: 1971, Second Lunar Science Conference, Houston (unpublished).

[10] Sippel, R. F. and Spencer, A. B.: 1970, Proc. Apollo 11 Lunar Science Conference, Geochim. Cosmochim. Acta Suppl. 1 3, 2413.

[11] Lang, H. and Kressin, G.: 1955, Z. Phys. 142, 380.

[12] Geake, J. E. and Walker, G.: 1966, Geochim. Cosmochim. Acta 30, 927.

[13] Crookes, W.: 1879, Phil. Trans. Roy. Soc. 170, 641.

[14] Buddhue, J. D.: 1941, Am. J. Sci. 239, 839.

[15] Gallup, J.: 1936, J. Opt. Soc. Am. 26, 213.

[16] Smith, J. V. and Stenstrom, R. C.: 1965, J. Geol. 73, 627.

[17] Sippel, R. F.: 1965, Rev. Sci. Inst. 36, 1556. 
[18] Long, J. V. P. and Agrell, S. O.: 1965, Min. Mag. 34, 318.

[19] Greer, R. T., Staley, W. G., and Vand, V.: 1967, Amer. Ceramic Soc. Bull. 46, 829.

[20] Derham, C. J. and Geake, J. E.: 1964, Nature 201, 62.

[21] Blair, I. M. and Edgington, J. A.: 1970, Proc. Apollo 11 Lunar Science Conference, Geochim. Cosmochim. Acta Suppl. 1 3, 2001.

[22] Nash, D. B. and Greer, R. T.: 1970, Proc. Apollo 11 Lunar Science Conference, Geochim. Cosmochim. Acta Suppl. I 3, 2341.

[23] Dugdale, R. A.: 1966 J. Materials Sci. 1, 160.

[24] Geake, J. E. and Walker, G.: 1967, Proc. Roy. Soc. 296, 337. 